\title{
An experimental study of the influence of loading direction on the thermohydrodynamic behaviour of twin axial groove journal bearing
}

\author{
A Arab Solghar ${ }^{1 *}$, F P Brito ${ }^{2}$, J C P Claro ${ }^{2}$, and S A Gandjalikhan Nassab ${ }^{1}$ \\ ${ }^{1}$ Department of Mechanical Engineering, School of Engineering, Shahid Bahonar University, Kerman, Iran \\ ${ }^{2}$ CT2M, Center for Mechanical and Material Technology, University of Minho, Guimarães, Portugal
}

The manuscript was received on 3 December 2010 and was accepted after revision for publication on 7 February 2011.

DOI: $10.1177 / 1350650111401970$

\begin{abstract}
An experimental assessment of the influence of angle between the groove axis and the load line on the thermohydrodynamic behaviour of twin groove hydrodynamic journal bearings has been undertaken. At nine different loading direction angles, the oil-bush interface temperature profiles, oil outlet temperature, maximum bush temperature, total flow rate, and oil flow rate through each groove were measured for variable applied load and oil supply pressure while the feeding temperature was kept constant $\left(40^{\circ} \mathrm{C}\right)$. To the authors' knowledge, this is the first study of the influence of loading direction on the performance of journal bearing with two axial grooves in which the flow rate were measured in each groove for different working conditions under laminar regime. It was found that the variation of loading direction has a strong effect on the bearing performance. Under some running conditions, negative lubricant flow rate (hot oil reflux) at one groove was detected. This seldom-reported phenomenon was found to affect the bearing performance dramatically. Increasing supply pressure yielded a temperature decrease, especially for high loads, and sometimes prevented the occurrence of hot oil reflux.
\end{abstract}

Keywords: hydrodynamics lubrication, thermal effects, experimental results, journal bearings

\section{INTRODUCTION}

Hydrodynamic journal bearings are widely used to support rotating shafts, especially under high applied load and shaft rotational speed. Bearing behaviour is greatly influenced by the way the oil is supplied to the bearing gap. It is frequent to perform the oil supply through a pair of axial grooves. This geometry allows shaft rotation in both directions, being also generally accepted that a pair of grooves provides a more efficient cooling of the bearing than one single groove.

\footnotetext{
*Corresponding author: Department of Mechanical Engineering, School of Engineering, Shahid Bahonar University, Kerman, Iran. email: alireza_arabsolghar@yahoo.com
}

Several experimental analyses considering thermohydrodynamic (THD) characteristic of journal bearing with single axial groove have been reported in literature, notably by Mitsui et al. [1], Ferron et al. [2], and Syverud and Tanaka [3].

Tonneson and Hansen [4] carried out an experimental investigation of the THD characteristics of circular journal bearing. In their experiments, the shaft and bush surface temperatures, mid-plane pressure distribution, eccentricity, and lubricant flow rate were measured and the effects of speed, load, viscosity, and oil inlet geometry on these parameters were carried out.

In an experimental work, Gethin and El-Deihi [5] examined the thermal performance of journal bearing with two axial grooves under varying load 
direction conditions. It was found that apart from speed and load magnitude, loading direction also had a significant effect on film temperature excursions. Their work was limited to high-speed bearings.

The estimation of heat transfers from the oil film to the bush and the journal were carried out by Fitzgerald and Neal [6]. They concluded that the axial temperature variation was negligible but the circumferential temperature variation could be very significant.

Ma and Taylor $[\mathbf{7}, \mathbf{8}]$ experimentally studied the THD performance of journal bearings with two axial grooves. The results were provided for various values of applied load, shaft rotational speed, oil inlet temperature, and pressure.

Costa et al. [9] studied the influence of oil supply conditions on the THD performance of a single axial groove journal bearing. It was shown that oil supply conditions affect bearing performance parameters in different ways and the effect of supply pressure on minimum film thickness is dependent on groove location. They concluded that an axial groove located at a positive angle from the upper load line in the direction of shaft rotation can lead to reductions in maximum temperature, peak hydrodynamic pressure, and full-film region.

More recently, Brito et al. [10] experimentally assessed the performance of journal bearing considering different values of oil inlet temperature and pressure. Temperature and pressure distributions in the centre line of bearing were presented in that work. Also, the variations of shaft locus, power loss, and journal temperature were provided for various operating conditions.

The lack of information concerning individual flow rate at each groove prove to be somewhat limitative of the discussion of the results. The way oil is distributed to the grooves of twin groove journal bearings is likely to affect deeply the temperature profiles and the cooling effect of the inlet lubricant. Also, some works pointed out to a possible occurrence of negative flow rate at one of the grooves under some conditions $[7,8]$ but no evidence was presented in support of this claim. For tilting-pad journal bearings, Fillon et al. [11] already demonstrated that the temperature at the inlet zone of a high-loaded pad could be greater than the temperature of the exit of the previous lowloaded pad, due to the large recirculating flow.

The role of each groove on the behaviour of twin axial groove journal bearings started being assessed in a work by Brito et al. [12], where they performed individualized flow rate measurements at each groove. In the range of applied load studied, the total flow rate in the bearing showed only slight variations while the partial flow rates through the upstream and the downstream grooves varied dramatically with negative values being observed in the upstream groove for the high load range. To the best authors' knowledge, this was the first documented report on the occurrence of negative flow rate in a groove of multi-grooved bearings. This phenomenon was further described in another work by Brito et al. [13] where they also compared single and twin axial groove bearings. They found that the total measured flow rate was nearly the same in both cases and that the twin groove journal bearing showed an added risk of seizure when operating under extreme load and low supply pressure. All these works point out to the high sensitivity of the role of grooves in bearing performance depending on working and oil feed conditions.

The main goal of this study is to address the need of having a better understanding of the role of loading direction on the THD characteristics of journal bearings. The angle between the axis of the grooves and the load line (loading direction angle) is here designated simply as the groove angle $(\gamma)$ and measured in the direction of shaft rotation. This angle is normally $90^{\circ}$ in twin groove journal bearings. However, it can assume other values, namely when there is permanent or temporary change in the load direction. The study of this parameter with the help of individualized groove flow rate is likely to provide a deep insight into the role of each groove, and more generally, of lubricant supply conditions on bearing behaviour.

To the best of authors' knowledge, no previous experimental study has assessed these particular phenomena for full journal bearings, particularly for varying load direction. Therefore, this study describes a thorough investigation on the influence of loading direction on twin groove journal bearings including an assessment of the flow rate distribution through each one of the grooves and its influence on its thermal behaviour.

\section{TEST RIG}

A schematic view of the experimental test rig existing in the Tribology Laboratory of the University of Minho is represented in Fig. 1. Although this apparatus has already been used in many works (Claro and Miranda [14] and Costa et al. [15]), several of its capabilities, especially those related to data acquisition, signal treatment, flow rate measurement, and supply temperature regulation, were significantly improved for this study.

The geometric parameters, operating and supply conditions, as well as lubricant properties, are presented in Table 1. The rig allows the regulation of rotational speed, applied load, oil supply pressure, 


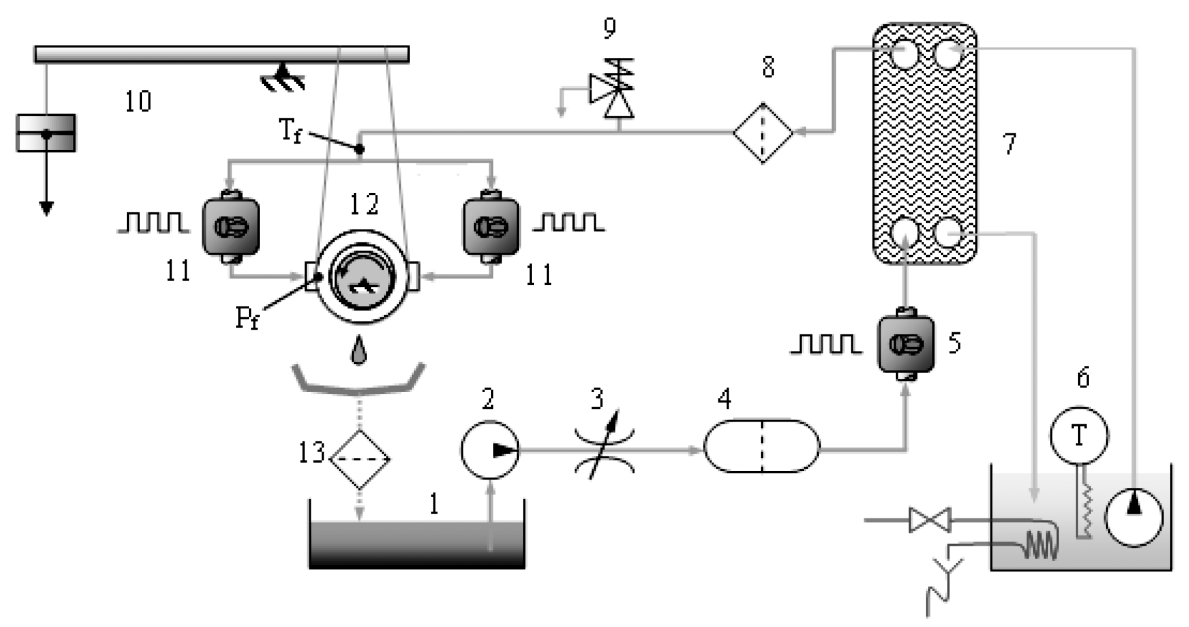

Fig. 1 Schematic overview of the test rig. (1) Oil tank; (2) gear pump; (3) flow regulation valve; (4) pulse damper; (5) electric pulse gear flow meter (total flow rate); (6) temperature controlled water bath with outer circulation; (7) plate heat exchanger; (8) filter; (9) relief valve; (10) loading system; (11) electric pulse gear flow meters; (12) instrumented bearing system; and (13) filter

Table 1 Main bearing characteristics, lubricant properties, and operating conditions

\begin{tabular}{|c|c|c|c|}
\hline \multicolumn{2}{|l|}{ Parameter } & \multirow{2}{*}{$\begin{array}{l}\text { Units } \\
-\end{array}$} & \multirow{2}{*}{$\begin{array}{l}\text { Value/span } \\
0.5\end{array}$} \\
\hline Groove length/diameter ratio & $a / b$ & & \\
\hline Bush width/diameter ratio & $b / d$ & - & 0.8 \\
\hline Bearing diametric clearance & $C_{d}$ & $\mu \mathrm{m}$ & 86 \\
\hline Inner bush diameter (nominal) & $d$ & $\mathrm{~mm}$ & 50 \\
\hline Outer bush diameter & $D$ & $\mathrm{~mm}$ & 100 \\
\hline Groove circumferential extension/diameter ratio & $w / d$ & - & 0.2 \\
\hline Rotational speed & $N$ & $\mathrm{r} / \mathrm{min}$ & 4000 \\
\hline Applied load & $F$ & $\mathrm{kN}$ & $0.4-4$ \\
\hline Lubricant type & - & - & ISO VG 32 \\
\hline Oil supply temperature & $T_{f}$ & ${ }^{\circ} \mathrm{C}$ & 40 \\
\hline Oil supply pressure & $P_{f}$ & $\mathrm{kPa}$ & 100,300 \\
\hline Dynamic viscosity at $30^{\circ} \mathrm{C}$ & $\mu_{f}$ & $\mathrm{Ns} \mathrm{m}^{-2}$ & 0.0467 \\
\hline Dynamic viscosity at $75^{\circ} \mathrm{C}$ & $\mu_{f}$ & $\mathrm{Ns} \mathrm{m}^{-2}$ & 0.0083 \\
\hline Specific mass & $\rho$ & $\mathrm{kg} \mathrm{m}^{-3}$ & 875 \\
\hline Specific heat & $c_{p}$ & $\mathrm{~J} / \mathrm{kg}^{\circ} \mathrm{C}$ & 1943 \\
\hline Thermal conductivity & $k$ & $\mathrm{~W} / \mathrm{m}^{\circ} \mathrm{C}$ & 0.13 \\
\hline Ambient temperature & $T_{a}$ & ${ }^{\circ} \mathrm{C}$ & $30-55$ \\
\hline
\end{tabular}

and supply temperature. The measured performance parameters were the temperature at the oil-bush interface, the oil outlet temperature $\left(T_{\text {out }}\right)$, the oil flow rate at each groove, and the total oil flow rate.

The shaft was driven by a $0.95 \mathrm{~kW}$ variable speed motor via a transmission belt. The speed was regulated through an inverter drive and kept within a range of $\pm 10 \mathrm{r} / \mathrm{min}$ of the nominal speed. The shaft, made of $\mathrm{X} 22-\mathrm{CrNi17}$ stainless steel, was rigidly mounted on by two preloaded conical rolling bearings that assured an adequate stiffness to the system. The bush was made of RG5G-CuSn5ZnPb bronze. The bush diameter, the shaft diameter, and cylindricity were measured using a 'Mitutoyo BHN706' coordinate measuring machine with a resolution of
$0.1 \mu \mathrm{m}$. The oil used was ISO VG 32 (Galp Hidrolep 32 - see Table 1 for details).

The loading arrangement relies on a cantilever system on which dead weights are applied. The cantilever acts on the bush body through a closed-loop steel wire. The loading system was calibrated using a high-precision load cell with an error of less than $\pm 0.5 \mathrm{~N}$.

The supply pressure $\left(P_{f}\right)$ was regulated by a restrictor valve and monitored by pressure transducers located at the interior of each groove. $P_{f}$ was kept within an interval of variation of $\pm 0.004 \mathrm{MPa}$.

The supply temperature $\left(T_{f}\right)$ was regulated via a thermostatic bath with outer circulation passing through a plate heat exchanger in order to heat the 

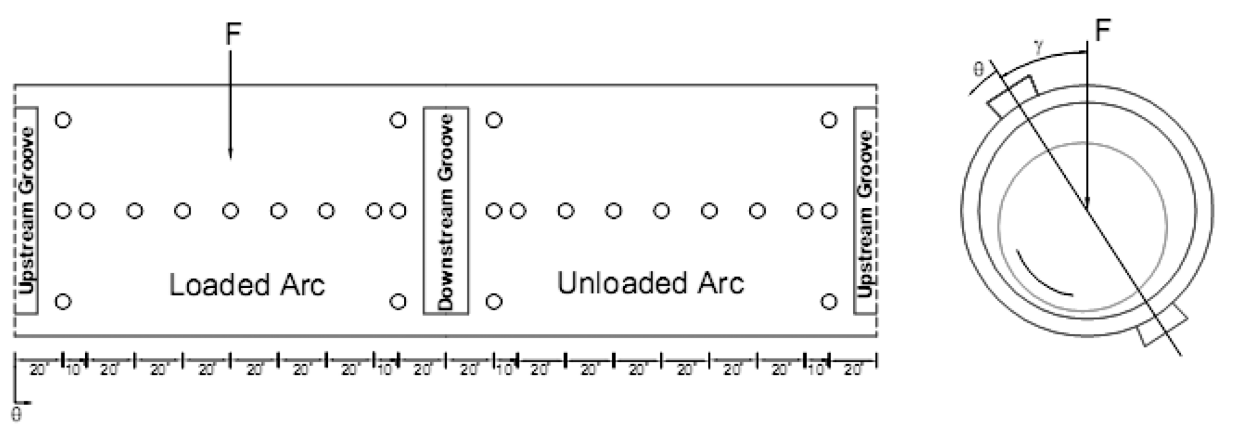

Fig. 2 Angular location of the thermocouples at the inner surface of the bush (unwrapped view)

oil that was being supplied to the bearing. The temperature of the bath was regulated so that $T_{f}$ was kept within a range of $\pm 0.1^{\circ} \mathrm{C}$ from the set point. $T_{f}$ was monitored by three thermocouples, one located in the main feeding pipe, just upstream of the point where the flow is separated in two branches to feed each groove and two other thermocouples, one on each groove, just before the groove entrance.

The measurements were always made under a steady state regime. In order to achieve this, startup times were set for thermal stabilization. Between tests, parameters such as temperature and flow rate were monitored until stabilization was achieved.

The oil flow was measured by three gear flow meters (repeatability 0.03 per cent), suitable for low flow rate measurements, linked to the data acquisition system. One flow meter was attached to the main feed line, while the other two were located in each branch in order to measure partial flow rates. To ensure accurate flow rates, measurements were performed during $35 \mathrm{~s}$. The difference between the total flow rate and the sum of the partial flow rates was below 1.5 per cent in most of the cases.

The temperature field was monitored by type $\mathrm{K}$ thermocouples attached to a data acquisition system. The repeatability of the measured values was within $\pm 1^{\circ} \mathrm{C}$. The temperature at the oil-bush interface was measured at the locations depicted in Fig. 2. The thermocouples were placed inside fully drilled holes, flush with the inner bush surface. Another set of thermocouples was positioned so, as to measure the oil outlet temperature and the environment temperature.

\section{RESULTS AND DISCUSSION}

Various results obtained for different working conditions and oil supply parameters will now be presented and discussed. In order to evaluate the behaviour of each oil supply groove and temperature variation across the mid-plane of the bearing, a parametric study was performed on three major parameters that are known to clearly affect the THD performance of journal bearing: groove angle, applied load, and oil supply pressure.

\subsection{Oil flow rate}

Figure 3 shows the variation of oil flow rate with increasing load, for constant shaft speed $(4000 \mathrm{r} /$ min), oil supply temperature $\left(40^{\circ} \mathrm{C}\right)$, and oil supply pressure (100 and $300 \mathrm{kPa})$, and at different values of groove angle. Analysing the effect of load on the flow rate, it can be seen that the total oil flow rate curve shows a typical evolution with load as presented in other works $[6,8]$, with an initial increase, a stabilization, and a smooth decline.

It is interesting to note that the two grooves display a totally different behaviour with loading conditions. This is rarely reported phenomenon, in which the lubricant flows out of the bearing gap through the groove instead of flowing into it, and it occurs when the hydrodynamic pressure field at the vicinity of the groove exceeds the supply pressure.

As shown in Fig. 3, at the groove angles lower than $80^{\circ}$, the downstream flow rate is always negative for light range of applied loads. In all groove angle cases, as load increases, the flow rate at the downstream groove begins with a low values and then increases. This behaviour can be explained by the fact that, as load increases, greater hydrodynamic pressure values tend to occur on the loaded arc of the bearing. This causes an increase in oil leakage with its subsequent renewal at the groove located immediately downstream of the pressure build-up zone. Furthermore, as load increases, the changes in shaft locus (typical of load increase) cause the gap at the downstream groove to increase, while the pressure build-up zone tends to develop on a smaller angular extension, away from the downstream groove region, further facilitating oil entrance from this groove. However, the slope of the downstream flow rate curve differs markedly as 
(a)
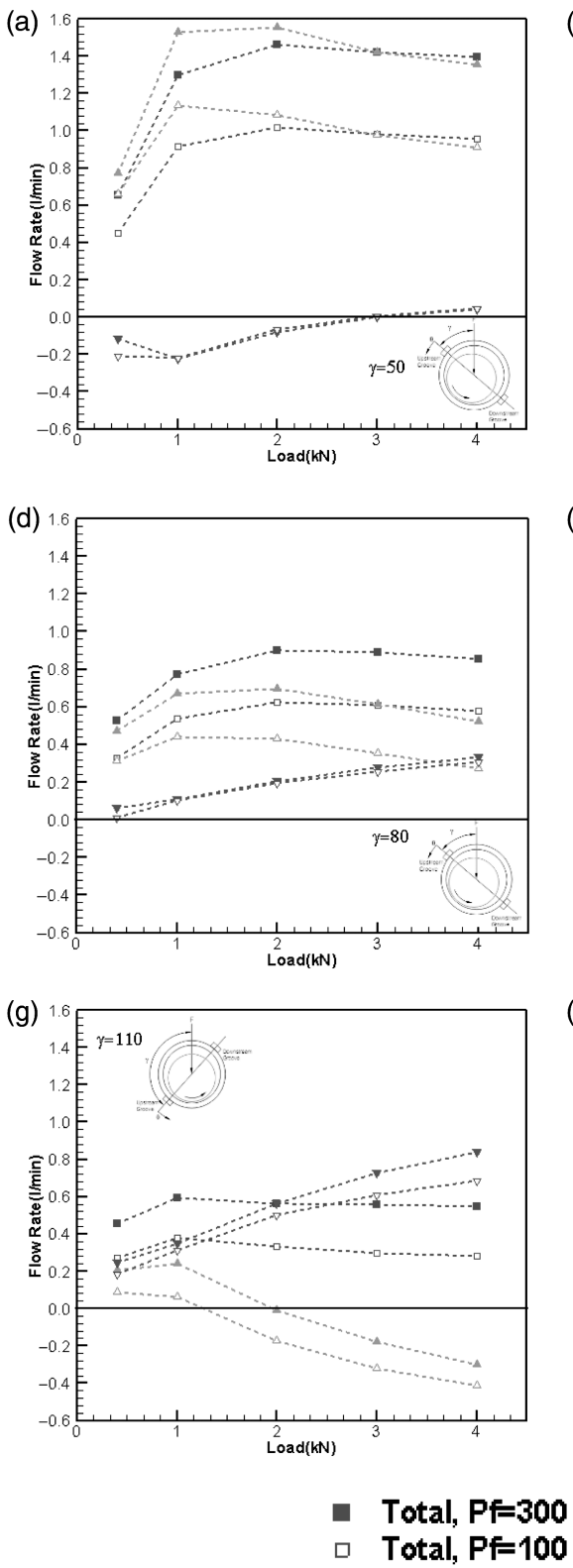

(b)

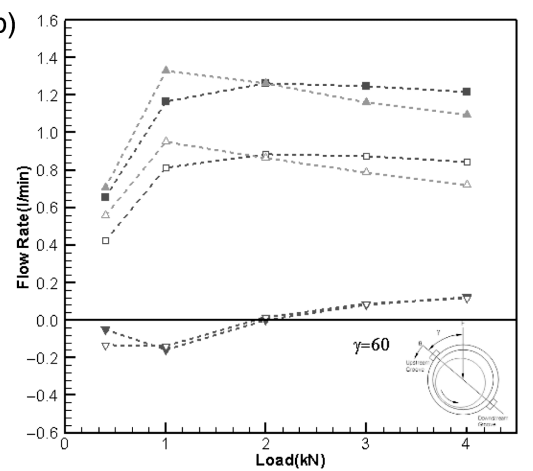

(e)

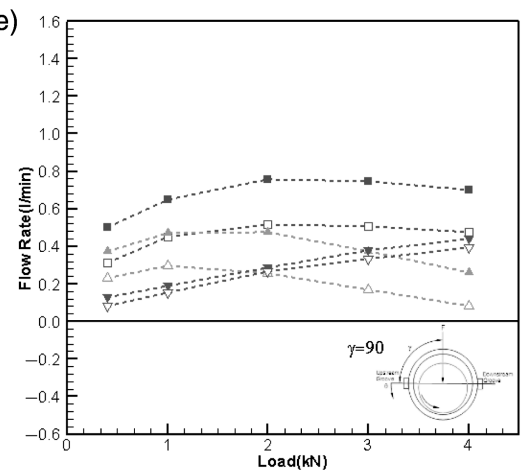

(h)

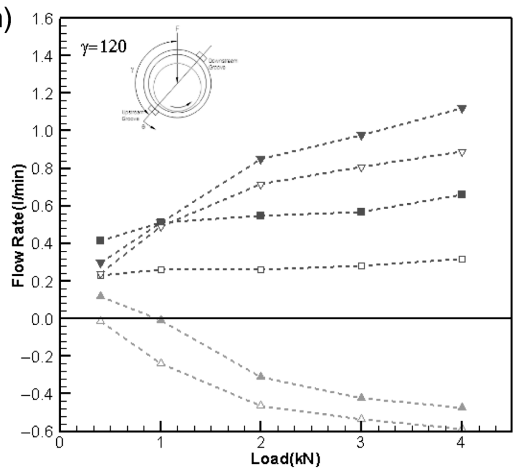

(c)

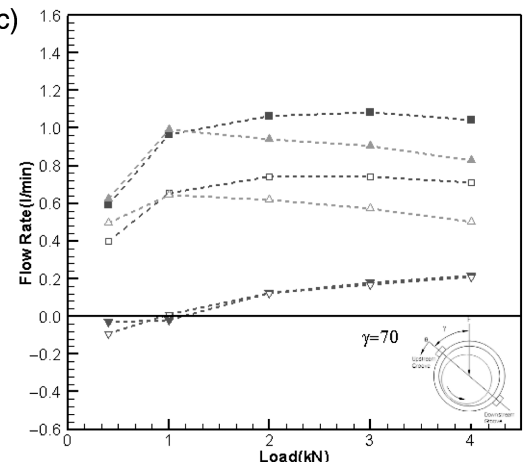

(f)

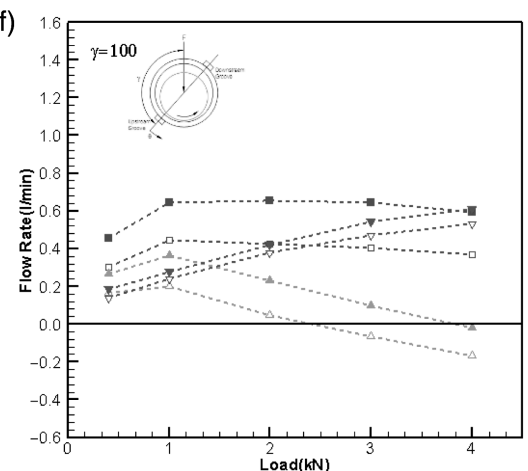

(i)

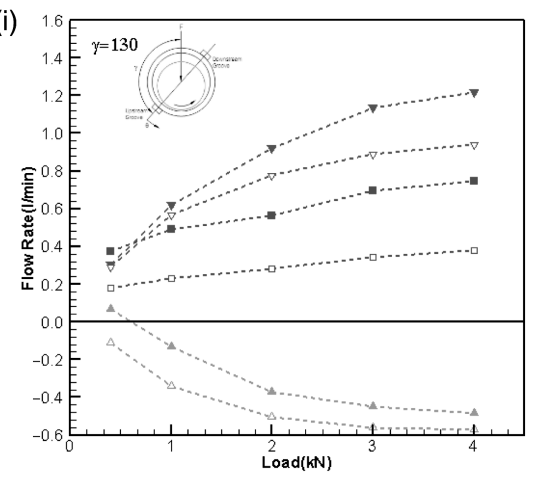

Upstream, $P f=300$ $\triangle$ Upstream, Pf 100

\section{Downstream, Pf=300}

$\checkmark$ Downstream, Pf=100

Fig. 3 Total, upstream, and downstream flow rates as a function of applied load and groove angle

groove angle varies. For instance, the downstream flow rate changes from -0.117 to $0.040 \mathrm{Lmin}^{-1}$ (slope $=0.043$ ) at $\gamma=50^{\circ}$, and from 0.301 to $1.218 \mathrm{Lmin}^{-1}$ (slope $=0.254$ ) for $\gamma=130^{\circ}$, when load rises from 0.4 to $4 \mathrm{kN}$, respectively, and supply pressure is set to $300 \mathrm{kPa}$. Therefore, the groove angle deeply affects the oil flow rate of the downstream groove. In fact, the downstream flow rate starts being almost negative for low $\gamma$ but always increases with increasing $\gamma$, ceasing to be negative for $\gamma \geqslant 80^{\circ}$.

The opposite occurs for the upstream groove, it starts being high for low $\gamma$ and reduces with the increase of $\gamma$; it is even almost negative for $\gamma \geqslant 100^{\circ}$ and for almost all load ranges. From Fig. 3, a linear fall in the flow rate through the upstream groove is observed, when load starts increasing above $1 \mathrm{kN}$ for $\gamma \leqslant 110^{\circ}$ and for all ranges of loads at $\gamma>110^{\circ}$. The decrease of this flow rate with increasing load is associated with the corresponding change of location and magnitude of the hydrodynamic pressure field. As the load increases, there is an increase in pressure generation and a decrease in attitude angle, causing the pressure build-up zone to move upstream, closer to the groove region. Above some critical load, the pressure generated in the upstream groove region exceeds the value of the supply pressure. This causes some of the oil to flow out of the bearing through the oil groove. Moreover, Fig. 3 displays that the increase 
of oil supply pressure always improves the total flow rate and also mitigates the negative flow rate in both grooves.

Thus, as illustrated in Fig. 3, the total lubricant flow rate considerably varies according to the loading direction angle, in which it reduces sharply with the rise of loading direction angle. For instance, in the case of an applied load of $4 \mathrm{kN}$, the amount of total flow rate increases 2.53 and 1.85 times when the groove angle increases from $50^{\circ}$ to $130^{\circ}$, while the feeding pressures are kept constant at 100 and $300 \mathrm{kPa}$, respectively.

Negative oil flow rate in the grooves is an undesirable behaviour in various ways. Concerning lubrication needs, the region near the location of minimum film thickness $\left(H_{\mathrm{min}}\right)$ is the critical one. For instance, when flow rate at the upstream groove is negative, oil is being supplied only at the non-active part of the film, where it will increase power loss due to viscous dissipation. At the same time, oil is being retrieved from the film instead of being supplied to it, just upstream of the location where it is mostly needed. Furthermore, this may happen under severe operating conditions, i.e. high applied loads, raising the failure risk of the system.

The impact of the occurrence of negative oil flow rate can be further assessed by analysing the temperature field, which is deeply affected by the way the oil is delivered to the system.

Under low loads, the occurrence of negative flow rate should not be much of a problem, as the bearing is far from seizure risk. Under these conditions, the best option seems to be the use of low values of supply pressure and high values of gamma, leading to total flow rates that could be as low as $0.18 \mathrm{Lmin}^{-1}$. Under high loads, however, avoiding negative flow rate is paramount, as it strongly degrades bearing performance and raises seizure risk. For these cases, gamma should not be higher than $90^{\circ}$. The lower the gamma, the safest the bearing will operate and the more $P_{f}$ could be reduced. In order to reduce the pump size, the best option would be to have the lowest total flow rate while still avoiding negative flow rate. For the conditions tested, this would happen for $P_{f}=100 \mathrm{kPa}$ and $\gamma=90^{\circ}$ with a minimum of total flow rate around $0.4 \mathrm{Lmin}^{-1}$. For loads higher or $P_{f}$ values lower than those tested, gamma should be reduced accordingly.

\subsection{Temperature field}

A global view of the temperature profiles at the midplane of the film-bush interface for a wide set of loading directions is shown in Fig. 4. The present discussion is focused on the $4000 \mathrm{r} / \mathrm{min}$ tests and three different loads $0.4,2$, and $4 \mathrm{kN}$. Oil supply temperature and pressure are kept constant at $40^{\circ} \mathrm{C}$ and $300 \mathrm{kPa}$, respectively.

For the case of $\gamma \leqslant 90^{\circ}$, when the bearing is lightly loaded $(0.4 \mathrm{kN})$, it can be seen from Fig. 4 that the maximum temperature ( $\left.T_{\max }\right)$ occurs in the unloaded arc. This is so because bearings tend to display a high attitude angle, which causes the minimum film thickness to be located after the downstream groove region. Moreover, the temperature fade across the downstream groove is smaller than upstream groove due to lower flow rate in downstream groove (recall Fig. 3). For example, in the case of $\gamma=70^{\circ}$, cooling effects of $6.5^{\circ} \mathrm{C}$ and $2.4^{\circ} \mathrm{C}$ are observed for upstream and downstream grooves, respectively.

However, for $W<1 \mathrm{kN}$ and $\gamma \geqslant 90^{\circ}$, the maximum temperature occurs at the loaded arc near the downstream groove's edge, at an angular distance of about $20^{\circ}$. In these cases, the temperature fade becomes more pronounced across downstream groove such that for $\gamma=120^{\circ}$, the temperature fades are $0.7^{\circ} \mathrm{C}$ and $6.7^{\circ} \mathrm{C}$ across the upstream and downstream grooves, respectively.

Obviously, from Fig. 4, as load increases, the maximum temperature increases in loaded arc, caused by an increase in heat dissipation. The location of $T_{\max }$ moves further upstream, which may be caused by the decrease in attitude angle. Due to this fact, the region where heat dissipation is more intense occurs further upstream. In addition, the temperature fall across the downstream groove becomes more evident as load increases. The greater temperature fall across the downstream groove is mainly due to the increase of flow rate. Therefore, a general lowering of the unloaded arc temperature level is observed as load rises. Furthermore, in the case of $F=4 \mathrm{kN}$, the smallest and largest temperature fades across the downstream groove are $10.0^{\circ} \mathrm{C}$ and $3.1^{\circ} \mathrm{C}$, taking place at $\gamma=50^{\circ}$ and $90^{\circ}$, respectively.

Moreover, as groove angle rises from $50^{\circ}$ to $130^{\circ}$, the location of maximum temperature moves from $10^{\circ}$ to $80^{\circ}$ further upstream, respectively. This is due to the fact that by the increase of groove angle, the upstream groove gets closer to the minimum film thickness.

Surprisingly, at $\gamma \geqslant 100^{\circ}$, temperature always rises after the downstream groove; this is because of the occurrence of negative flow rate at the upstream groove, i.e. the hot oil that flows out of the bearing through the upstream groove mixes with the new oil inside the supply system piping. This induces a temperature rise of the oil supply temperature to the opposite groove.

As shown in Fig. 4, for the case of $F=4 \mathrm{kN}$, groove angles $90^{\circ}$ and $120^{\circ}$ yield the lowest and the highest 
(a)

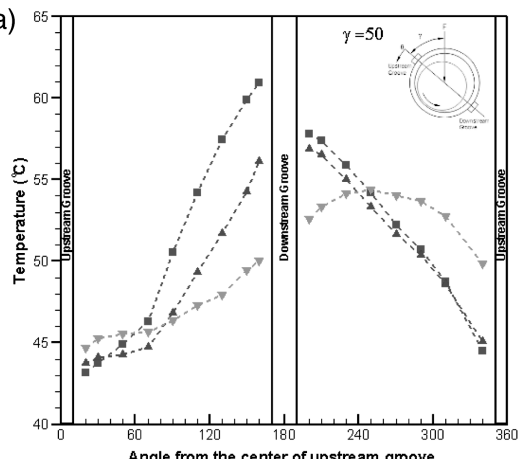

(d)

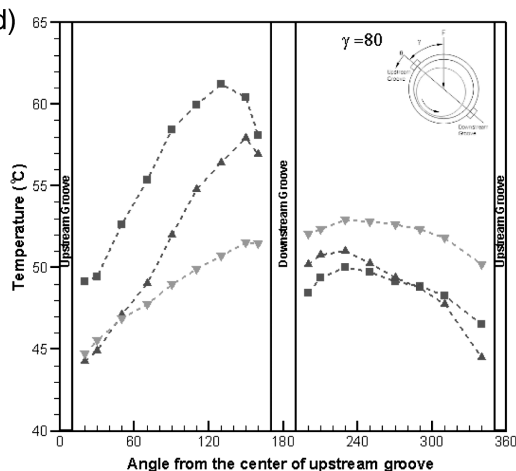

(g)

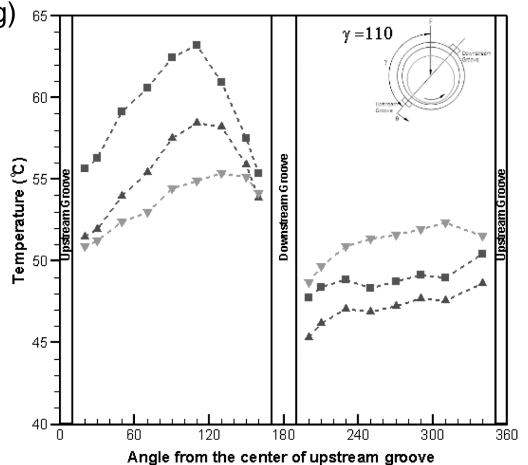

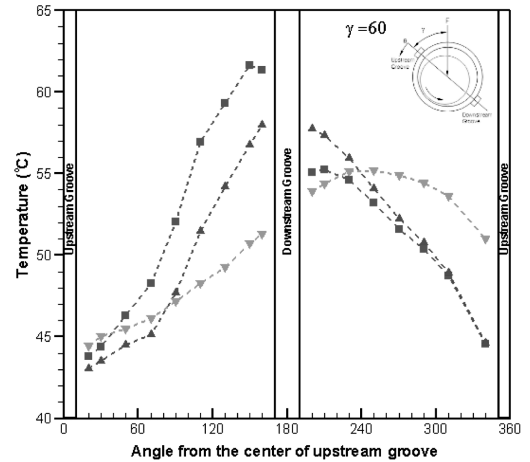

(e)

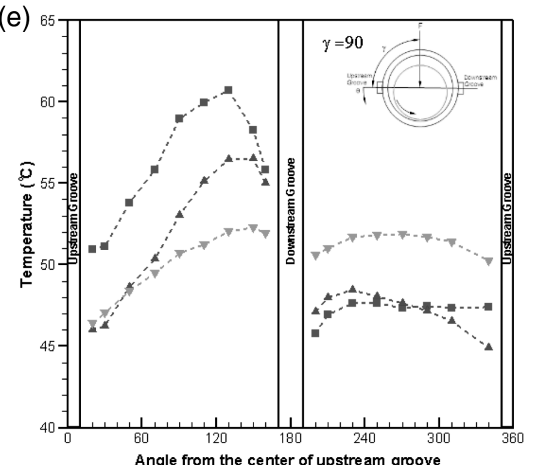

(h)

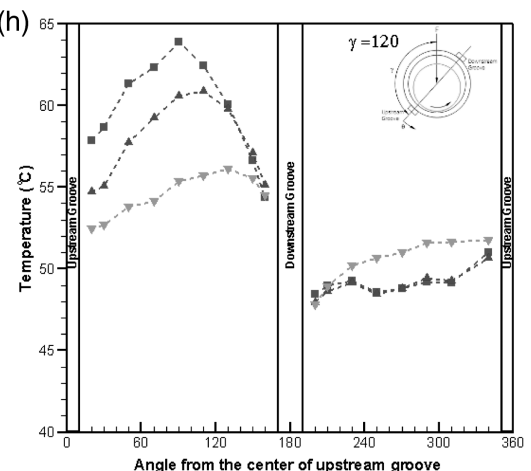

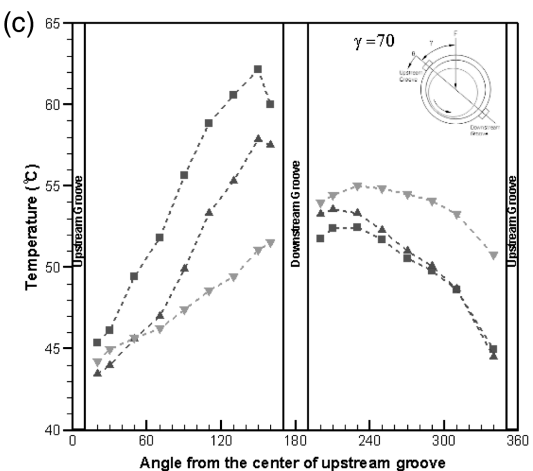

(f)

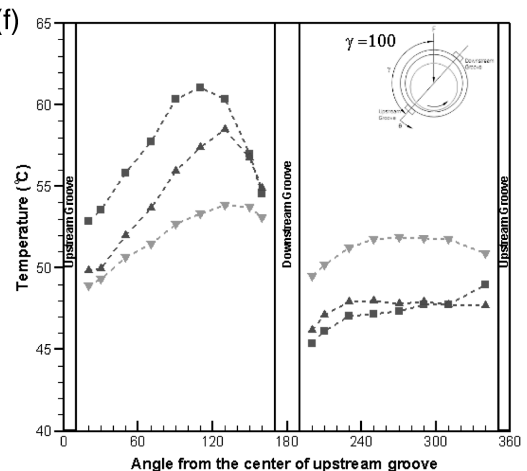

(i)

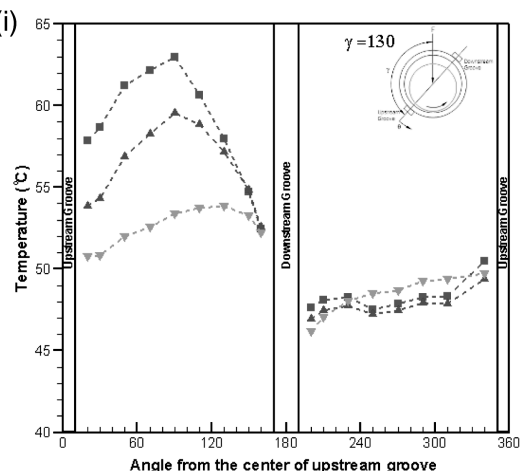

$W=4.0 \mathrm{kN}$

$\Delta \mathrm{W}=2.0 \mathrm{kN}$

$\nabla W=0.4 \mathrm{kN}$

Fig. 4 Temperature distribution at the mid-plane of the bearing as a function of applied load and groove angle

values of the maximum temperatures $60.6^{\circ} \mathrm{C}$ and $63.8^{\circ} \mathrm{C}$, respectively.

The maximum temperature $\left(T_{\max }\right)$ and oil outlet temperature $\left(T_{\text {out }}\right)$ are also particularly affected by groove angle, which intensify with rise of loading direction angle. This is mainly explainable by the flow rate which is also remarkably influenced by the groove angle, as previously illustrated in Fig. 3 . There are the regions of Fig. 3 where negative flow rate is observed especially for the upstream groove with $\gamma \geqslant 90^{\circ}$ and for the downstream flow rate for lightly loaded bearing at $\gamma \leqslant 80^{\circ}$. As explained earlier, in these tests, the hot lubricant flowing out of the bearing through the groove, mixed with the fresh lubricant at the feeding pipe, effectively raises the temperature of the lubricant supplied to the opposite groove. This feedback phenomenon is contributed to a global rise of the bearing temperature. As supply pressure increases, this phenomenon is mitigated. This is illustrated in the diagrams of Fig. 5, which represents the temperature at the inlet of each groove.

One of the consequences of hot oil reflux from one of the grooves is the effective rise of the feeding temperature in the opposite groove. In fact, the hot oil flowing out of the bearing through a groove mounts up the feeding pipe, mixing with the fresh oil feeding (which is at a temperature $T_{f}$ ) and is refed to the opposite groove at a temperature which is actually higher than feeding temperature. 
(a)

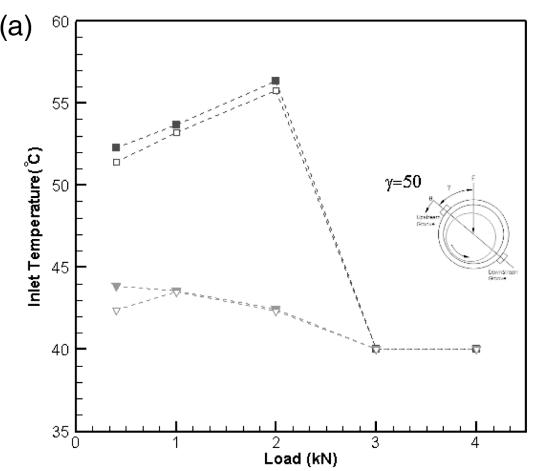

(d)

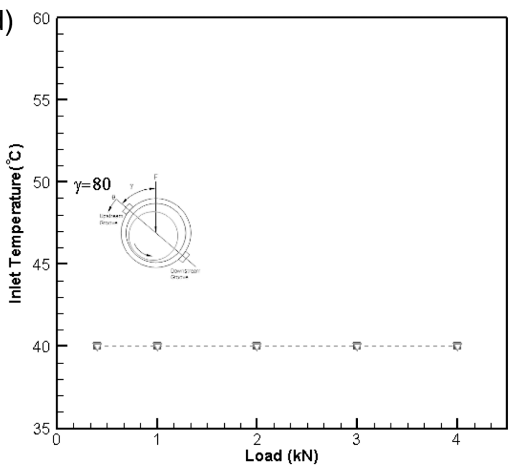

(g)

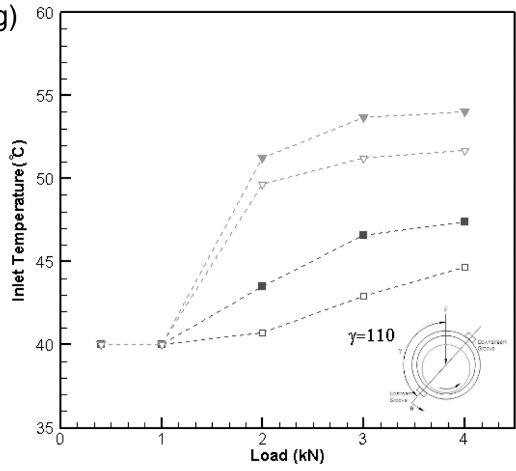

(b)

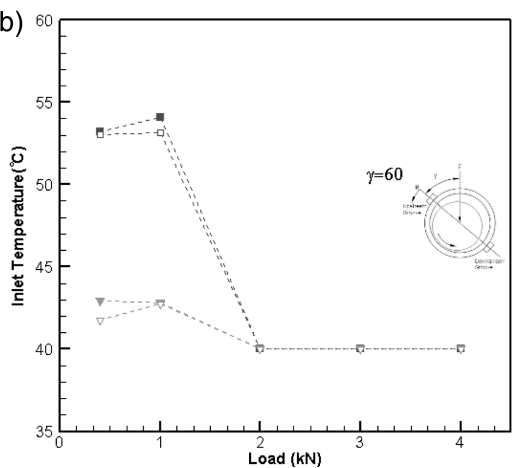

(e)

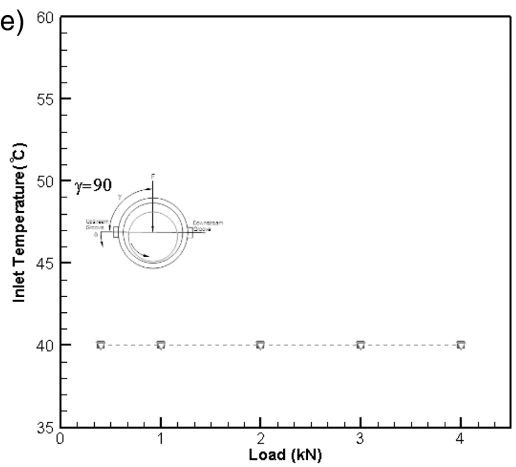

(h)

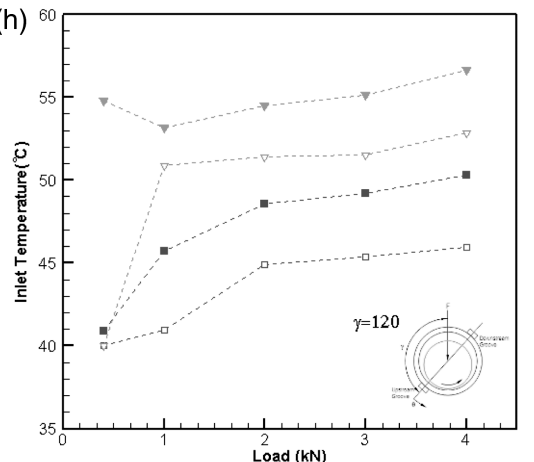

(c)

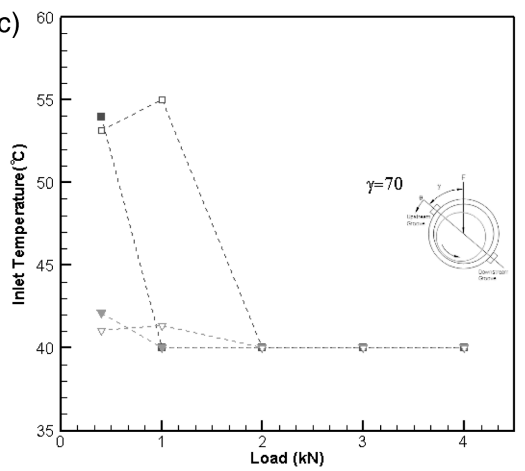

(f)

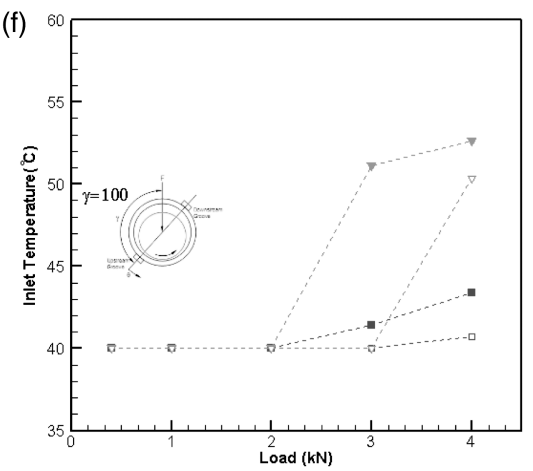

(i)

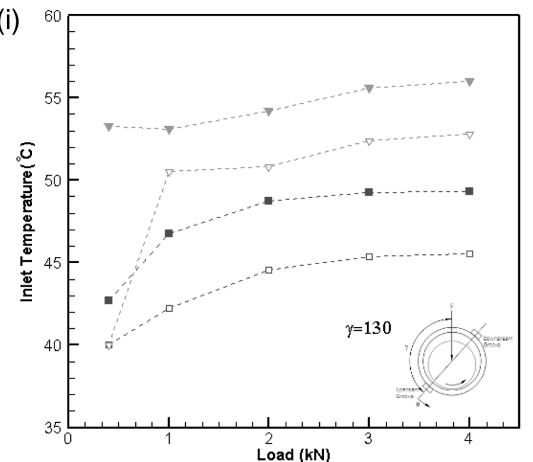

Upstream Groove, Pf=100

$\checkmark$ Upstream Groove, $\mathrm{Pf}=\mathbf{3 0 0}$

- Downstream Groove, $\mathrm{Pf}=100$

ㅁownstream Groove, $\mathrm{Pf}=\mathbf{3 0 0}$

Fig. 5 Changes in effective feeding temperature at one groove due to negative flow rate at the opposite groove (highest value corresponds to the temperature at the inlet of the groove with negative flow and the lowest value corresponds to the temperature at the inlet of the groove with positive flow rate)

The cases for which a negative flow rate occurred can be easily detected, because both grooves display temperatures that fairly exceed the feeding temperature, $T_{f}\left(40^{\circ} \mathrm{C}\right)$. For instance, the inlet temperature at $\gamma=130^{\circ}$, for $4 \mathrm{kN}$ applied load, are $49.3^{\circ} \mathrm{C}$ and $45.5^{\circ} \mathrm{C}$ for $P_{f}=100$ and $300 \mathrm{kPa}$, respectively. Therefore, the actual temperature of the oil supplied to the positive flow rate groove will depend not only on the temperature of the hot oil reflux but also on the value of the flow rates.

It can be seen in Fig. 6 that feeding pressure undoubtedly affects the temperature level of the bearing. Analysing Fig. 6, it can be seen that the increase of feeding pressure yields to the decrease of both $T_{\max }$ and $T_{\text {out }}$, with the latter decreasing more intensely than the former. The general temperature decrease is due to the increase in flow rate already observed in Fig. 3. Therefore, it is natural that $T_{\text {out }}$, which is a good indicator of the mean lubricant temperature, decreases more intensely than $T_{\max }$. There is an increase in $T_{\max }$ and $T_{\text {out }}$ with an increase of applied load, which is associated to the increase in eccentricity and therefore, of heat dissipation. 
(a)

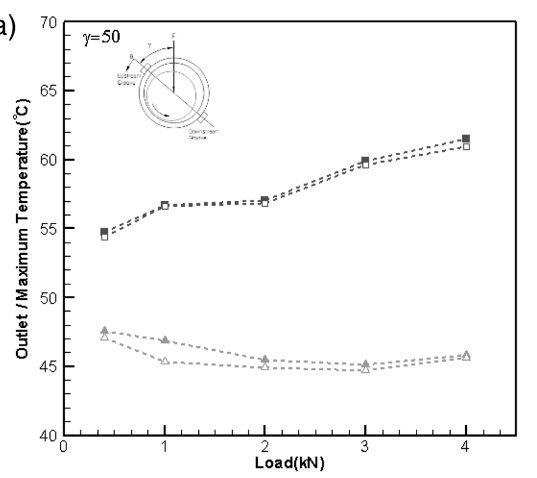

(d)

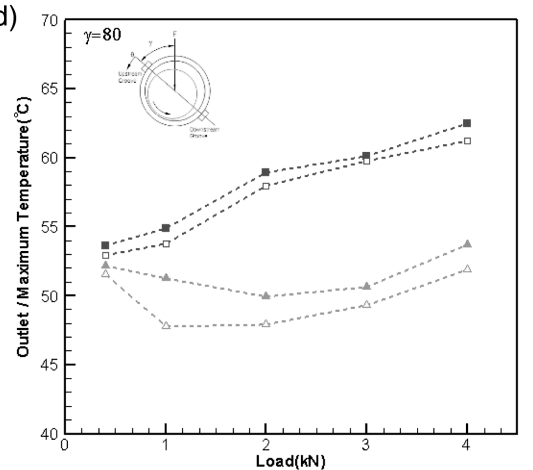

(g)

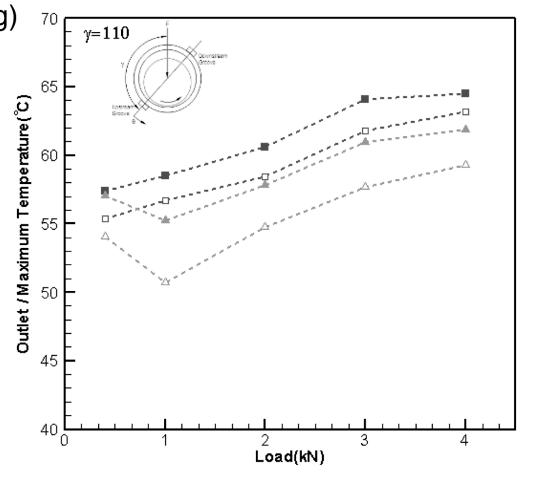

(b)

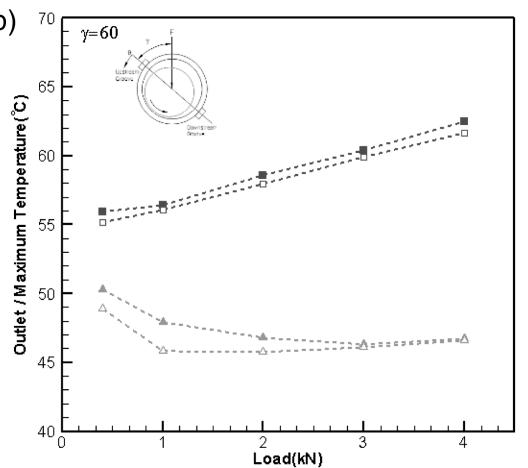

(e)

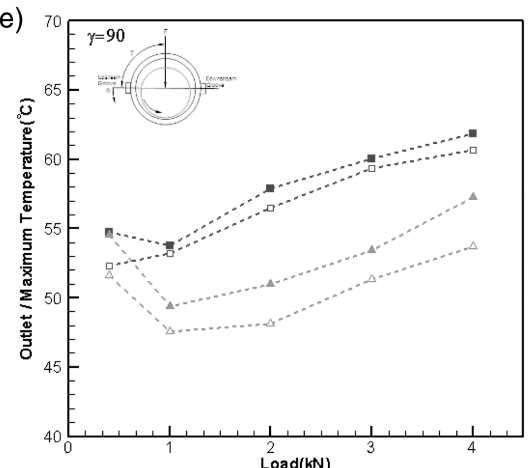

(h)

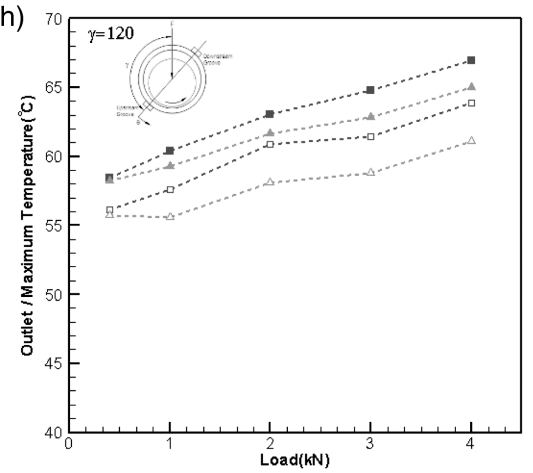

(c)

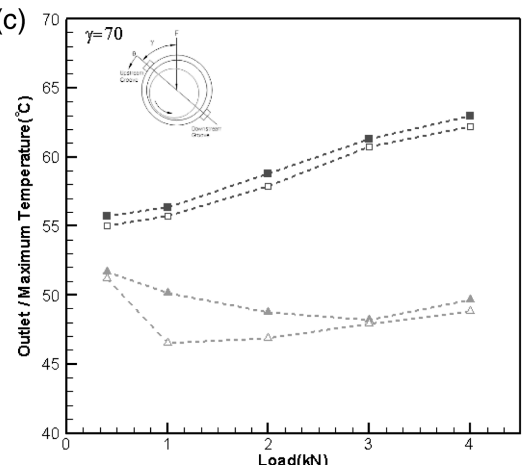

(f)

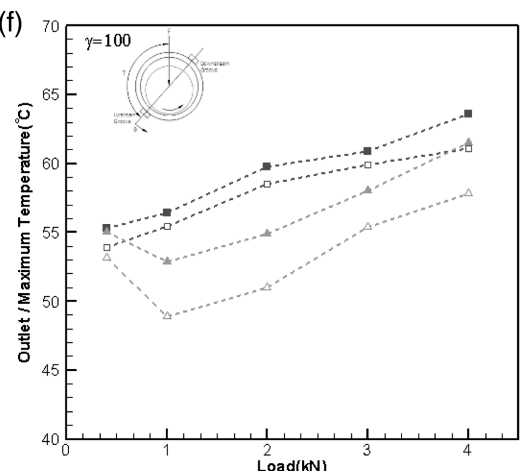

(i)

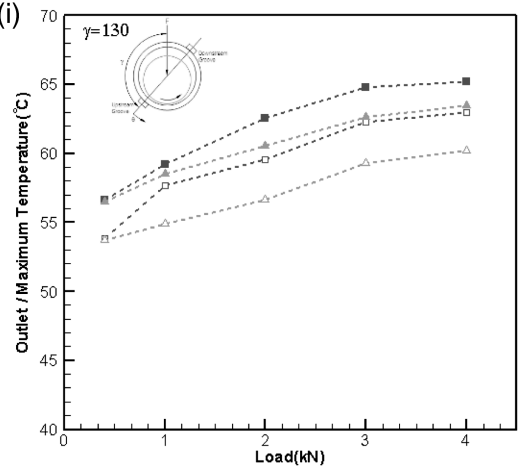

Tmax, Pf=100 kPa

T $\operatorname{Tmax}, \mathrm{Pf}=300 \mathrm{kPa}$

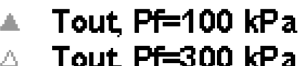

Fig. 6 Maximum temperature of bush-oil interface and oil outlet temperature as a function of applied load and groove angle

\section{CONCLUSIONS}

As concluding remarks, it can be stated that: The effect of groove angle on the total and partial flow (flow through each axial groove) rates for several loads was presented. The general trend found is that increasing groove angle tends to decrease the flow rate at the upstream groove and tends to increase the flow rate at downstream groove. Hot oil reflux (negative flow rate) occurs on both grooves (although, naturally, never simultaneously) under some conditions. The flow rate trends were mainly explained by the proximity to the pressure build-up zones and their locations relative to each groove.
In the case of the lower values of loading direction angle $\left(\gamma<80^{\circ}\right)$, the flow rate at upstream groove is much higher than that at the downstream groove. This is so, because the latter groove is right in the midst of the pressure build-up zone.

For $\gamma \geqslant 100^{\circ}$, the flow rate at the upstream groove is negative for nearly the whole load range. This constitutes the least desirable situation, because oil is being retrieved from the bearing gap instead of being fed to it just upstream of the region, where it would be most necessary: the active land of the bearing and more precisely, the minimum film thickness region. Under high loads, this could even induce bearing seizure. 
The cases where oil reflux occurred in one of the grooves are easily recognizable because the temperature at the inlet of the corresponding groove is very high, there is no temperature decrease across the groove, and there is an effective rise of the feeding oil temperature in the opposite groove due to the mixing of reflux and fresh supply oil. The overall temperature level is also higher than in those cases where no oil reflux occurs.

It was found that the worst working conditions in terms of $T_{\max }$ are angles in excess of $100^{\circ}$.

The bearing performance showed to strongly deteriorate with groove angles in the range of $100^{\circ}-130^{\circ}$. In these cases, negative flow rate (hot oil reflux) was detected in the upstream groove for nearly the whole range of loads tested. The oil reflux at the downstream groove is less deleterious for bearing performance as this groove feeds the non-active land of the bearing and tends to disappear as load increases.

The optimum value of groove angle possibly lies somewhere between $50^{\circ}$ and $90^{\circ}$.

The presented results are extremely relevant for bearing design. In fact, the phenomenon of negative flow rate that can strongly raise the risk of seizure has been seldom reported and never studied with the depth presented in this study.

(C) Authors 2011

\section{REFERENCES}

1 Mitsui, J., Hori, Y., and Tanaka, M. Thermohydrodynamic analysis of cooling effect of supply oil in circular journal bearings. ASME J. Tribol., 1983, 105, 414-421.

2 Ferron, J., Frêne, J., and Boncompain, R. A study of the thermohydrodynamic performance of a plain journal bearing. Comparison between theory and experiments. ASME J. Tribol., 1983, 105, 422-428.

3 Syverud, T. and Tanaka, M. Experimental investigation of the effect of shaft heating and cooling on single bore journal bearing. Wear, 1997, 207, 112-117.

4 Tonneson, J. and Hansen, P. K. Some experiments on the steady state characteristics of a cylindrical fluidfilm bearing considering thermal effects. ASME J. Tribol. Tech., 1981, 103, 107-114.
5 Gethin, D. T. and El-Deihi, M. K. I. Thermal behavior of a twin axial groove bearing under varying loading direction. Proc. IMechE, Part A: J. Power and Energy, 1990, 204, 77-90.

6 Fitzgerald, M. K. and Neal, P. B. Temperature distributions and heat transfer in journal bearings. ASME J. Tribol., 1992, 114, 122-130.

7 Ma, M. T. and Taylor, C. M. An experimental investigation of thermal effects in circular and elliptical plain journal bearing. Tribol. Int., 1996, 29(1), 19-26.

8 Ma, M. T. and Taylor, C. A theoretical and experimental study of thermal effects in a plain circular steadily loaded journal bearing. In Proceedings of the IMechE Seminar on Plain bearings - energy efficiency and design, Institution of Mechanical Engineers, 10 November 1992, pp. 31-44 (Mechanical Engineering Publications Limited, London).

9 Costa, L., Fillon, M., Miranda, A. S., and Claro, J. C. P. An experimental investigation of the effect of groove location and supply pressure on the THD performance of a steadily loaded journal bearing. ASME J. Tribol., 2000, 122, 227-232.

10 Brito, F. P., Miranda, A. S., Bouyer, J., and Fillon, M. Experimental investigation of the influence of supply temperature and supply pressure on the performance of a two-axial groove hydrodynamic journal bearing. ASME J. Tribol., 2007, 129, 98-105.

11 Fillon, M., Bligoud, J. C., and Frene, J. Experimental study of tilting-pad journal bearings - comparison with theoretical thermoelastohydrodynamic results. ASME J. Tribol., 1992, 114, 579-588.

12 Brito, F. P., Miranda, A. S., Claro, J. C. P., and Fillon, M. The role of each groove on the behavior of twin axial groove journal bearings. In Proceedings of the IV Congresso Ibérico de Tribologia (IBERTRIB 2007), Bilbau, Spain, 21-22 June 2007.

13 Brito, F. P., Miranda, A. S., Claro, J. C. P., and Fillon, M. Experimental study of the influence of groove flow rate on the performance of a single and a twin groove journal bearing. In Proceedings of the STLE Annual Meeting, Cleveland Convention Center, Ohio, 18-22 May 2008.

14 Claro, J. C. P. and Miranda, A. S. Analysis of hydrodynamic journal bearings considering lubricant supply conditions. Proc. IMechE, Part C: J. Mechanical Engineering Science, 1993, 207, 93-101.

15 Costa, L., Miranda, A. S., Claro, J. C. P., and Fillon, M. Temperature, flow, and eccentricity measurements in a journal bearing with a single axial groove at $90^{\circ}$ to the load line. Lubr. Sci., 2003, 15(2), 147-161. 